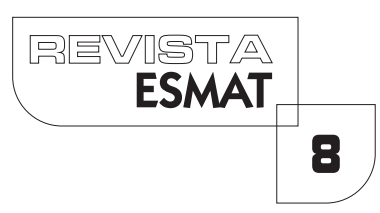

\title{
INCIDENTE DE RESOLUÇÃO DE DEMANDAS REPETITIVAS - NOVO PARADIGMA DE SOLUÇÃO DAS AÇÕES DE MASSA E DA RAZOÁVEL DURAÇÃO DO PROCESSO
}

\section{Esmar Custódio Vêncio Filho}

Juiz auxiliar da Presidência do Tribunal de Justiça do Estado do Tocantins; coordenador do Grupo de Monitoramento e Fiscalização do Sistema Carcerário do Estado do Tocantins (GMF); coordenador do Conselho Nacional de Justiça dos mutirões carcerários dos estados do Tocantins (20 I 0 e 20 I 4), Rio Grande do Sul (20 I I), São Paulo (20 I I) e Rio Grande do Norte (20 I 2). Email:esmarfilho@uol.com.br

\section{RESUMO}

Há tempos que as demandas de massa ou repetitivas têm sido uma preocupação para o Poder Judiciário, por serem responsáveis pelo acúmulo de serviço e morosidade. $\bigcirc$ novel instituto de Incidente de Resolução de Demandas Repetitivas priorizou os princípios constitucionais processuais, de modo a garantir amplo acesso ao Judiciário e especialmente solucionar conflitos de forma mais célere e impedir novas demandas, a fim de assegurar a observância do princípio da razoável duração do processo, aprimorar a efetividade das decisões judiciais e ressalvar o primado da dignidade da pessoa humana.

PALAVRAS-CHAVE: Princípios constitucionais processuais. Duração razoável do processo. Demandas de massa. Incidente de resolução de demandas repetitivas. Processamento.

\section{ABSTRACT}

There are times that the demands of mass or repetitive a preoccupation has been for the Judiciary, since responsible for the accumulation of service and slowness. The new institute of Incident of Resolution of Repetitive Demands prioritized the constitutional processual principles, ensuring broad access to Judiciary and specially solving conflicts of faster form and obstructing new demands, securing the observance of the principles of the reasonable duration of the process, perfecting the effectiveness of the judicial decisions, excepting the primacy of the dignity of the human person.

KEYWORDS: Procedural constitutional principles. Average duration of the process. Mass demands. Incident of repetitive demands of resolution. Processing. 


\section{INTRODUÇÃO}

A necessidade de se dar maior celeridade aos julgamentos dos feitos, mormente pela crescente facilidade de acesso aos meios judiciais de solução de conflitos pós Constituição Federal, de 1988, (CF) e de legislações ordinárias editadas com o fim de facilitar a tramitação e apreciação das demandas, o que gerou considerável aumento do volume já existente, levou o legislador a dar relevante valor aos princípios constitucionais processuais como os da duração razoável do processo, ampla defesa e economia processual, quando da elaboração do Novo Código de Processo Civil (NCPC).

Os congressistas, assistidos pela comissão de juristas formada para o estudo, discussões e elaboração do novo CPC, incluíram em seu texto os mencionados princípios constitucionais processuais, ressaltando as garantias e fundamentos já previstos na CF concernentes à efetividade das decisões judiciais e à estrita observância da cidadania.

Nessa nova conduta processual civil, o Incidente de Resolução de Demandas Repetitivas (IRDR) facilita e democratiza ainda mais o acesso à justiça, consubstanciando a garantia constitucional do processo, já que, a partir dele, possibilita-se um espectro de acesso ao judiciário nunca antes experimentado, além de abreviar o curso das lides de mesma fundamentação, baseadas em direitos similares, configurando respeito, em última e ampla análise, aos direitos fundamentais da pessoa humana.

$O$ perfil garantista, definido pela CF em relação aos fundamentos processuais, migrou definitivamente para o NCPC. Em seu artigo $I^{\circ}$ estabelece que "O processo civil será ordenado, disciplinado e interpretado conforme os valores e as normas fundamentais estabelecidos na Constituição da República Federativa do Brasil (...)".

Esse alinhamento é repetido várias vezes no bojo do texto, ex vi, art. $3^{\circ}$ Princípio da Inafastabiliade da Jurisdição (art. 5०, XXXV, CF); art. 26, I - Princípio do Devido Processo Legal (art. 5०, LIV, CF); arts. $9^{\circ}$ e 98, VIII - Princípios da Ampla Defesa e do Contraditório (art. 50, LV, CF); art. $4^{\circ}$ - Princípio da Celeridade/Duração Razoável do Processo (art. 50, LXXVIII, CF); arts. $7^{\circ}$ e 927, § $4^{\circ}$ - Princípio da Isonomia (art. 5 , CF); arts. I I e 194 - Princípio da Publicidade (art. 93, IX, CF); arts. II , 489, § $1^{\circ}$, e 927, § $4^{\circ}$ - Princípio da Motivação das Decisões (art. 93, IX, CF); art. 369 - Princípio da Prova Lícita (art. 5, LVI, CF); art. 496 - Princípio do Duplo Grau de Jurisdição (art. 5 , LV, CF).

Além desses princípios, o novo CPC ainda tratou expressamente de outros e reforçou os já antes existentes, mesmo que implicitamente, como os 
INCIDENTE DE RESOLUÇÃO DE DEMANDAS REPETITIVAS - NOVO PARADIGMA DE SOLUÇÃO DAS AÇÕES DE MASSA E DA RAZOÁVEL DURAÇÃO DO PROCESSO

princípios da cooperação e lealdade das partes, da dignidade da pessoa humana, da legalidade e da eficiência.

Denota-se claramente que o pós-positivismo constitucionalizou o processo civil. A própria exposição de motivos do NCPC menciona expressamente que, dentre os vários objetivos do novo texto processual, estava a inclusão dos princípios constitucionais processuais. Tanto é assim, que foi criada a parte geral de onde se extraem vários princípios constitucionais dessa natureza.

A necessidade de se ressaltar a constitucionalização do NCPC se dá para melhor perceber e entender os institutos nele contidos, em especial o Incidente de Resolução de Decisões Repetitivas.

O realce dos princípios constitucionais processuais no NCPC fica ainda mais claro quando o ministro Luiz Fux, presidente da comissão de juristas formada para a elaboração do NCPC, na Exposição de Motivos menciona que:

A necessidade de que fique evidente a harmonia da lei ordinária em relação à Constituição Federal da República fez com que se incluíssem no Código, expressamente, princípios constitucionais, na sua versão processual. Por outro lado, muitas regras foram concebidas, dando concreção a princípios constitucionais, como, por exemplo, as que preveem um procedimento, com contraditório e produção de provas, prévio à decisão que desconsidera da pessoa jurídica, em sua versão tradicional, ou "às avessas". (FUX, 20 I 0, p. I 5).

Há tempos tem-se percebido que o maior volume dos feitos em trâmite na justiça brasileira é representado pelas execuções fiscais e demandas repetitivas, sejam estas envolvendo pessoas físicas ou jurídicas, de direito público ou privado.

Constata-se isso desde a institucionalização da Súmula Vinculante como fonte jurídica de direito, introduzida na CF, em seu artigo I03A, pela Emenda Constitucional n 045, de 2004, e regulamentada pela Lei n I I .4 I 7, de 2006. Também naquela época, o descrédito na justiça nacional se dava não apenas pelo antagonismo das decisões proferidas em matérias semelhantes, mas também pelo abarrotamento de demandas, exteriorizando um judiciário pesado, lento e ineficiente.

Tendo como pano de fundo os mesmos princípios constitucionais/processuais também orientadores no NCPC, como os da celeridade, economia processual, isonomia e duração razoável do processo, a Súmula Vinculante, mesmo que de exclusiva competência do Supremo Tribunal Federal (STF), surgiu com a premente necessidade de empreender maior celeridade e eficácia aos julgamentos. 
As Sumulas Vinculantes, hoje em número de 46, mesmo que surgidas em meio a desconfianças e repulsas, representou um avanço na processualística nacional, porque deram a todos, especialmente aos jurisdicionados, a sensação de estabilidade dos julgamentos pelos mesmos encampados, desestimulando a judicialização desenfreada, desmotivada e sem proveito e o aventurismo jurídico, redundando na redução das lides e maior pacificação social.

Na mesma esteira de pensamento, fundamenta-se o recurso repetitivo (art. 543C, do (PC). Mesmo que tenha sua origem e razões idênticas à súmula vinculante, o recurso repetitivo não alcançou efetivamente seu principal objetivo, qual seja, inibir a judicialização de matérias já pacificadas no recurso representativo da controvérsia, posto que somente afetará os recursos suspensos, mas não evitará novas demandas, apenas novos recursos.

O Incidente de Resolução de Demandas Repetitivas (IRDR), mesmo que possuindo interseções com os recursos repetitivos, pois visam ao julgamento de matérias de massa, destes se distinguem essencialmente pela forma e local de processamento. Enquanto que os recursos repetitivos são processados no Superior Tribunal de Justiça (STJ), o IRDR será processado nos Tribunais Estaduais ou nos Tribunais Regionais Federais (TRFs).

Na mesma esteira das súmulas vinculantes e recursos repetitivos, o IRDR busca extirpar o congestionamento do Poder Judiciário, diante das demandas e situações tantas vezes repetidas e já discutidas, a fim de pacificar entendimentos, evitar a judicialização e conferir celeridade e segurança aos julgados.

As duas experiências (súmula vinculante e recurso especial representativo de controvérsia) serviram como base e origem para a institucionalização do IRDR, possibilitando ao Juízo de primeiro grau impedir, já no nascedouro, o processamento de matérias cuja tese de julgamento fora firmada pelo tribunal a que está vinculado.

Esse instituto, somado aos já existentes, certamente desestimulará os grandes litigantes, reduzindo não somente a ofensa ao próprio direito, mas ainda conduzirá à mediação e/ou conciliação pré-processuais, reduzindo o ajuizamento de demandas. Nesse mesmo sentido, a imposição das penas de litigância de má-fé, em razão do ajuizamento de demandas repetitivas com teses já devidamente fixadas, também desencorajaráa judicialização.

Nesse contexto, este artigo objetiva analisar o novel incidente de resolução de demandas repetitivas à luz de correlatos institutos jurídicos preexistentes, assim como da doutrina, jurisprudência e normas jurídicas similares, nacionais e internacionais. Por meio da pesquisa bibliográfica, a coleta de dados objetiva explicitar e edificar possibilidades a respeito da fundamentação teórica e do tema 
INCIDENTE DE RESOLUÇÃO DE DEMANDAS REPETITIVAS - NOVO PARADIGMA DE SOLUÇÃO DAS AÇÕES DE MASSA E DA RAZOÁVEL DURAÇÃO DO PROCESSO

tratados neste artigo.

O objetivo geral foca-se na compreensão do IRDR como um sucedâneo de outros institutos já instituídos em nosso sistema jurídico, envoltos dos mesmos objetivos de conter a judicialização de massa, observar a duração razoável do processo e dar aos julgamentos, não padronização, mas estabilidade.

Especificamente, o artigo busca, com base em análise jurídica e doutrinária, apresentar o IRDR como instituto essencial para a democratização e aperfeiçoamento da justiça brasileira, especialmente no que se refere às opções processuais, analisando suas fases e processamento.

\section{HISTÓRICO}

A diversidade de decisões proferidas ante uma mesma matéria litigiosa, além de estimular a judicialização, em verdadeira chicana, transparece ao jurisdicionado a desigualdade de tratamento, conduzindo ao descrédito não somente do Poder Judiciário, mas também da própria ideia de justiça.

O ministro do Supremo Tribunal Federal, Luiz Fux, presidente da Comissão de Juristas, criada para a elaboração do NCPC, em entrevista concedida ao programa Saiba Mais do STF, em 24/3/20 I5, se referiu ao IRDR como sendo a "menina dos olhos" do NCPC.

Antônio Pereira Gaio Júnior, ao se referir ao acúmulo de processos e à disparidade das decisões exaradas em relação ao mesmo direito, menciona que:

(...) somando-se à problemática quantitativa, tem-se a necessidade de melhor equalização das decisões judiciais aos casos concretos com nítida similitude, ou seja, nota-se, de muito, uma variedade de julgados com comandos discrepantes sobre uma mesma situação de direito, fortalecendo o sentimento de insegurança jurídica, realçado em sua face subjetiva, ou seja, na confiança legítima dos cidadãos quando à calculabilidade e previsibilidade dos atos dos poderes públicos, contrariando assim o próprio e verdadeiro escopo da visão democrática a que o processo, como instrumento de liberdade, deva encarnar e incansavelmente perquirir: o empenho à igualdade de todos perante o direito. (GAIOJÚNIOR, 20I l, p. 03).

O projeto do NCPC foi elaborado focando o princípio da isonomia, previsibilidade e, com maior enfoque ainda, na não judicialização e, consequentemente, na mediação e conciliação, especialmente as préprocessuais. Nesse sentido, o legislador pretende um processo civil, se necessário, mais enxuto, célere e justo. 
Na Exposição de Motivos do NCPC, a comissão destaca que "Está-se, aqui, diante de poderoso instrumento, agora tornado ainda mais eficiente, cuja finalidade é a de uniformizar a jurisprudência dos Tribunais superiores, interna corporis."

Nosso histórico, em relação às soluções das demandas de massa e/ou repetitivas, além de tímido, é recente. Temos a cultura da litigância e individualização das demandas, até mesmo porque, com o advento da CF, de 1988, a garantia de acesso ao Judiciário e a inafastabilidade da jurisdição aumentou vertiginosamente o número de ações que acabaram por inviabilizar os julgamentos, posto o Poder Judiciário encontrar-se despreparado para assimilar tamanha carga.

O desembargador do estado de Minas Gerais, Kildare Gonçalves Carvalho (2005), ressalva que a garantia de acesso à justiça "é a inafastabilidade ao acesso ao Judiciário, traduzida no monopólio da jurisdição, ou seja, havendo ameaça ou lesão de direito, não pode a lei impedir o acesso ao Poder Judiciário."

Por seu turno, Fredie Didier Júnior (2015) leciona que o Princípio da Inafastabilidade da Jurisdição "garante uma tutela adequada à realidade de direito material, ou seja, garante o procedimento, a espécie de cognição, a natureza do provimento e os meios executórios adequados às peculiaridades da situação litigiosa."

Desde então, tentou-se desestimular o acesso individual ao judiciário editando-se normas jurídicas que pudessem solver as questões de direito em um espectro mais amplo e célere, como as leis que disciplinaram a ação popular, ação civil pública, mandado de segurança coletivo, improbidade, Código de Defesa do Consumidor entre outras.

Mesmo assim, essas soluções não foram suficientes para reduzir a imensa quantidade de feitos que abarrotam o Judiciário, permanecendo a sensação de insegurança jurídica, desigualdade de julgamentos, morosidade e alto custo processual.

Sem limitar o acesso ao Judiciário, o IRDR soluciona os efeitos mediatos das demandas em massa ou repetitivas, reduzindo consideravelmente o prazo de julgamento, assim como da entrega efetiva da prestação jurisdicional já que, firmando-se a tese a respeito da matéria posta, haverá a solução vinculada e pacificada das demandas respectivas, impedindo, inclusive, o manuseio indevido de novas demandas fundadas no mesmo direito e recursos, sob pena de litigância de má-fé e ato atentatório à dignidade da justiça.

De forma imediata, o IRDR estimularia a mediação ou conciliação préprocessuais ou dissuadiria os litigantes contumazes à judicialização. 
INCIDENTE DE RESOLUÇÃO DE DEMANDAS REPETITIVAS - NOVO PARADIGMA DE SOLUÇÃO DAS AÇÕES DE MASSA E DA RAZOÁVEL DURAÇÃO DO PROCESSO

Musterverfahren é o correspondente da resolução de demandas repetitivas no direito alemão. $\bigcirc$ instituto Tedesco busca construir uma decisão geral sobre questões idênticas tratadas em várias demandas individuais, uniformizando o julgamento.

Antônio do Passo Cabral destaca o instituto da seguinte forma:

O escopo do Procedimento-Modelo é estabelecer uma esfera de decisão coletiva de questões comuns a litígios individuais, sem esbarrar nos ataques teóricos e entraves práticos da disciplina das ações coletivas de tipo representativo. Objetiva-se o esclarecimento unitário de características típicas a várias demandas isomórficas, com um espectro de abrangência subjetivo para além das partes. A finalidade do procedimento é fixar posicionamento sobre supostos fáticos ou jurídicos de pretensões repetitivas. (CABRAL, 2007, p. 132).

A Inglaterra, considerada berço das demandas coletivas, adotou o Group Litigation Orders (GLO), ordem para litígio em grupo, usada para ações de massa, congênere ao IRDR. As GLOs reúnem as partes em forma de listas de ações com registro em grupo, visando racionalizar o julgamento de processos que tratem das mesmas matérias de fato e de direito, quanto à questão comum que vincula todos do grupo.

Nesse sentido, manifestou-se Neil Andrews:

Essa questão comum geralmente envolve questões de responsabilidade ou de determinada categoria de prejuízo. Daí em diante, entretanto, cada autor deve declarar que sofreu perdas pessoais. $\bigcirc$ direito inglês não permite indenização por danos sem que haja provas de perdas reais sofridas por autores individuais (ANDREWS, 2009, p. 347).

Já nos Estados Unidos, o correspondente ao IRDR é o Multidistrict Litigation $(M D L)$, criado há mais de cinquenta anos para, da mesma forma que nós, solucionar um enorme número de ações judiciais, especialmente em razão da relação de consumo, adotando um procedimento que possibilita que demandas cíveis envolvendo uma ou mais matérias comuns de fato, em trâmite em diversos juízos, possam ser aglomeradas diante órgão jurisdicional uno, com competência instrutória.

Considerando nosso processo legislativo, algumas adequações acabaram por ser propostas e ocorridas na Câmara dos Deputados. Uma delas foi a definição do momento de instauração do IRDR. No Senado Federal, o entendimento era de que tal se desse quando se verificasse a potencial possibilidade de multiplicação de processos tratando sobre a mesma questão de 
direito. A Câmara dos Deputados, no entanto, entendia haver a necessidade de efetiva multiplicação de ações versando sobre idêntica matéria.

Além dessa efetiva multiplicação de processos, a Câmara dos Deputados exigia que houvesse no tribunal respectivo algum recurso ou causa originária versando sobre a mesma matéria. Em um visível temperamento das propostas, o instituto foi inserto no NCPC para manuseio quando houvesse efetiva repetição de processos que tratassem sobre a mesma matéria de direito.

Como dito alhures, o NCPC destacou, em sua parte geral, os princípios constitucionais processuais, dentre eles o da isonomia e segurança jurídica. A isonomia processual, que traz em seu bojo outros tantos princípios, como o contraditório e a ampla defesa, prima pela igualdade ampla e irrestrita de tratamento processual.

As decisões judiciais díspares sobre uma mesma matéria causavam sensação de desigualdade e descrédito na justiça. Nessa mesma linha, desdobrava-se a insegurança jurídica, pois não se sabia qual seria o resultado dos julgamentos. Essa imprevisão para análise de direitos similares é totalmente prejudicial ao processo, sendo necessária a estabilização dos pronunciamentos judiciais.

Alicerçado nessa premissa, o legislador, além de exigir para a instauração do IRDR efetiva repetição de processos com mesma controvérsia, também deveria destacar as ofensas à isonomia e segurança jurídica.

Urge mencionar que, mesmo limitada a controvérsia à questão unicamente de direito, seja ela qual for, tributário, previdenciário, consumidor, bancário, trabalhista, cível ou comercial, excluindo as de fato, nada obsta que haja formação do incidente para resolução de matéria de natureza processual.

Além das divergências de cabimento e momento de instauração do IRDR, o Senado Federal e a Câmara dos Deputados, quando da tramitação do NCPC, não fixaram o quantitativo de processos suficientes para a viabilidade do incidente. No procedimento similar britânico, exige-se uma movimentação pequena de tão somente de dez ou mais processos repetitivos.

A intencional lacuna processual deixou essa tarefa aos tribunais, os quais verificarão a necessidade de instauração do incidente ante o número de demandas repetitivas, mormente por sua consequência, já que todos os processos repetitivos ficarão suspensos, podendo inicialmente haver a rejeição o que, no entanto, não impede a instauração posterior se superadas as barreiras e impedimentos anteriores. 
INCIDENTE DE RESOLUÇÃO DE DEMANDAS REPETITIVAS - NOVO PARADIGMA DE SOLUÇÃO DAS AÇÕES DE MASSA E DA RAZOÁVEL DURAÇÃO DO PROCESSO

\section{ASPECTOS}

O cabimento e o processamento do IRDR serão analisados em capítulo próprio adiante. Pouco ou quase nada há de material doutrinário analisando o IRDR. Jurisprudência tampouco, porque o novo diploma processual encontrase cumprindo vacacio legis. No entanto, mesmo que com algumas similitudes com outros institutos já existentes e que possuem basicamente os mesmos objetivos, este novel instituto possui certas nuances próprias.

Para Bruno Dantas, integrante da Comissão de Juristas formada para a elaboração do NCPC, em entrevista concedida em 2010 ao site Consultor Jurídico, o IRDR será utilizado:

Sempre que houver uma demanda com potencial de se multiplicar, o juiz vai suscitar o tribunal e este vai decidir a tese jurídica que os juízes de todo o estado ou região vão aplicar no caso concreto, naturalmente exercendo seu papel de analisar provas e demais atos processuais. (DANTAS, 20 I0).

Essa posição, firmada antes de finalizado o texto sancionado, apenas o contrapõe no que se refere ao cabimento, já que o artigo 976, I, exige "efetiva repetição de processos que contenham controvérsia sobre a mesma questão unicamente de direito."

Mas sua fala, transcrita na entrevista concedida em 20l0, ainda continua atual quando, ao se referir aos recursos repetitivos e ao próprio IRDR, menciona que "Vai ser muito mais amplo e vai inibir as ações repetitivas." $O$ jurista ainda visualiza que "Se o novo mecanismo for um sucesso, como imaginamos que será, dificilmente vai chegar aos tribunais aquela avalanche de recursos iguais. Então, os repetitivos podem perder o sentido."

Realçando sua importância, o legislador estabelece que, mesmo havendo desistência ou abandono do incidente, tal não impede que o tribunal prossiga no processamento e enfrente o exame de seu mérito. A necessidade de se chegar à apreciação do incidente, evitando que seja também usado como manobra processual protelatória, é tão evidente que caberá ao Ministério Público assumir no caso de abandono ou desistência.

A inadmissibilidade do IRDR pela ausência de algum pressuposto não impedirá novo pleito caso superada a falha.

Os legitimados, enumerados no artigo 977, não se sujeitam ao pagamento de custas para aviarem os pedidos de incidente.

O IRDR não será admissível caso haja nos tribunais superiores questão material ou processual idêntica aguardando elaboração de tese em recurso. 
As questões submetidas ao IRDR serão comunicadas ao Conselho Nacional da Justiça (CNJ), possibilitando ampla divulgação não somente da instauração do incidente como também de seu julgamento. Os tribunais deverão elaborar banco eletrônico de dados específicos sobre as questões de direito submetidas ao incidente, comunicando o CNJ, para inclusão em cadastro.

Mesmo considerando que a instauração do incidente tem como consequência legal a suspensão dos processos que serão submetidos à tese, eventuais pedidos de tutela de urgência deverão ser dirigidos e decididos pelo Juízo onde tramita o processo suspenso.

A princípio, o incidente encamparia tão somente processos de determinada região ou submetidos a um tribunal específico. No entanto, caso haja processos no território nacional que versem sobre a mesma questão posta em deslinde no incidente, estes poderão ser suspensos.

Interessante é a figura do amicus curiae que poderá integrar o procedimento, requerendo juntada de documentos, produção de provas e outras diligências, participando efetivamente do processamento do incidente, com vistas a esclarecer a questão controvertida, o que demonstra o espírito participativo não somente deste instituto, mas como de todo NCPC.

Outro aspecto muito importante do IRDR e que faz com que ele se transforme em uma ferramenta excepcional de redução do tempo de processamento das demandas assim como da própria judicialização, é seu efeito vinculante (art. 985). Após o tribunal fixar a tese a ser aplicada aos processos suspensos, estes deverão ser julgados pelos juízes, de acordo com o entendimento firmado. Da mesma forma, posteriores ações ajuizadas contrariamente à tese firmada no IRDR serão julgadas improcedentes liminarmente (art. 332, III).

Após o julgamento do incidente, poderá haver inúmeros recursos aos tribunais superiores já que não há limitação legal nesse sentido. Porém, caberá ao tribunal de segundo grau selecionar alguns poucos recursos que encampem todos os argumentos de insurgência para remessa ao tribunal superior, sobrestando os demais recursos.

\section{PROCESSAMENTO}

pedido de instauração do incidente será dirigido ao presidente do Tribunal, pelo juiz ou relator, por ofício; pelas partes, Defensoria Pública ou Ministério Público, por petição, sendo que este último, quando não for o requerente, intervirá obrigatoriamente e assumirá a titularidade no caso de 
INCIDENTE DE RESOLUÇÃO DE DEMANDAS REPETITIVAS - NOVO PARADIGMA DE SOLUÇÃO DAS AÇÕES DE MASSA E DA RAZOÁVELL DURAÇÃO DO PROCESSO

desistência ou abandono.

A instauração e o julgamento do incidente terão ampla e específica divulgação e publicidade, por meio de registro eletrônico no Conselho Nacional de Justiça.

Após a distribuição do pedido, o colegiado do respectivo tribunal procederá ao juízo de admissibilidade do incidente, e um relator será designado o qual requisitará informações necessárias, intimará o Ministério Público e determinará a suspensão dos processos pelo prazo de um ano, voltando os feitos ao trâmite normal caso não haja julgamento ou decisão fundamentada do relator em contrário. Rejeitado o incidente, os processos suspensos voltarão a tramitar normalmente.

O relator disponibilizará às partes ou aos interessados (amicus curiae) oportunidade para, em quinze dias, juntarem documentos ou requererem diligências, podendo o relator, se for o caso, designar audiência.

$\mathrm{Na}$ audiência, o relator exporá o objeto do incidente facultando sustentação oral pelos autores, réus e interessados. Segue-se o julgamento e construção da tese vinculante, a qual deverá ser aplicada aos processos suspensos e às demandas posteriormente ajuizadas, as quais serão liminarmente julgadas improcedentes (art. 332, III), com possibilidade, inclusive, de imposição de multa por litigância de má-fé e/ou ato atentatório à dignidade da justiça.

$\mathrm{Da}$ decisão de julgamento do incidente caberá recurso especial ou extraordinário com efeito suspensivo, sendo que, para este último, presumirse-á repercussão geral da questão constitucional eventualmente discutida.

O mérito do recurso, apreciado pelo Superior Tribunal de Justiça ou Supremo Tribunal Federal, terá a tese aplicada a todas as lides em território nacional que tenham fundamento, parcial ou total, em direito no qual se fundou o incidente.

\section{CONCLUSÃO}

O IRDR já era esperado há muito tempo pelo ordenamento jurídico. Tanto é assim que os institutos correlatos preexistentes (súmula vinculante e recursos repetitivos) já indicavam a forte tendência em sua institucionalização.

O legislador pátrio é bastante cauteloso quando se trata de alterar ou inovar normas processuais e o costuma fazer em doses homeopáticas, analisando seus impactos e efeitos. Talvez por esta razão o IRDR, mesmo sendo um instituto há muito utilizado com sucesso pelo ordenamento jurídico estrangeiro, tenha demorado tanto a integrar a processualística civil nacional. 
Faltava essa importante ferramenta para otimizar a atuação jurisdicional de primeiro grau, já que o STF, tribunais superiores e até mesmo os tribunais de justiça, contavam com ferramentas de contenção de judicialização. A tese firmada em sede do IRDR surtirá efeitos excepcionais na instância singela já que servirá como limitador de demandas de massa, combatendo o inchaço do sistema judicial.

De qualquer forma, o IRDR é de longe a maior inovação trazida pelo NCPC e, após a fase inicial de adaptação de seu manuseio, certamente representará um grande avanço no aprimoramento da Justiça Brasileira, especialmente no que se refere à sua efetividade, eficiência e credibilidade.

\section{FLUXOGRAMA}

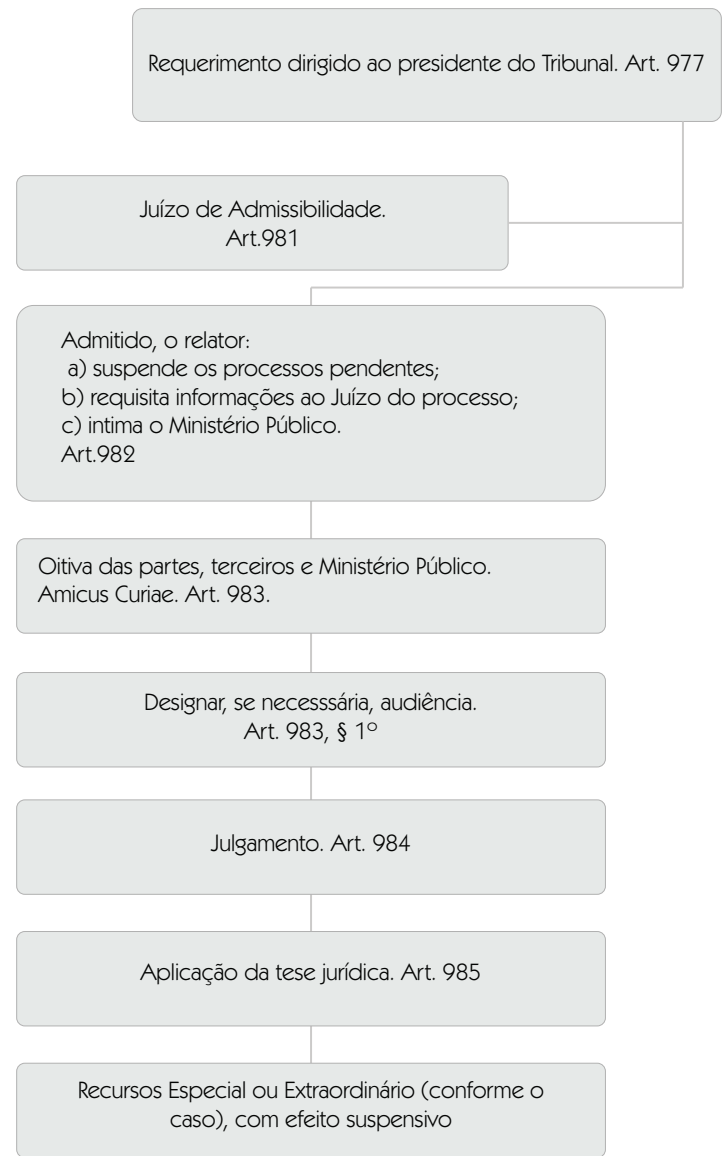


INCIDENTE DE RESOLUÇÃO DE DEMANDAS REPETITIVAS - NOVO PARADIGMA DE SOLUÇÃO DAS AÇÕES DE MASSA E DA RAZOÁVEL DURAÇÃO DO PROCESSO

\section{REFERÊNCIAS}

ANDREWS, Neil. O moderno processo civil: formas judiciais e alternativas de resolução de conflitos na Inglaterra; (orientação e revisão da tradução Teresa Arruda Alvim Wambier). São Paulo: Revista os Tribunais, 2009, p. 343.

BRASIL. Congresso Nacional. Senado Federal. Presidência. Comissão de Juristas Responsável pela Elaboração de Anteprojeto de Código de Processo Civil. Exposição de motivos. 20l0. Disponível em $<w w w . s e n a d o . g o v . b r / s e n a d o / n o v o c p c / p d f / a n t e p r o j e t o . p d f>$ Acesso em 26 abr. 2015.

JORNAL DA JUSTIÇA. Programa Saiba Mais. STF. Disponível em: <HTTP://youtu.be/Rr8EQEoFilo>. Publicado em: 24 mar. 20 I5. Acesso em 25 abr. 2015.

CABRAL, Antonio do Passo. O novo procedimento-modelo (Musterverfahren) alemão: uma alternativa às ações coletivas. Revista de processo. São Paulo, v. I 47, pp. I23- | 46, 2007.

CARVALHO, Kildare Gonçalves. Direito constitucional. I I ${ }^{a}$ ed., rev. e atual. Belo Horizonte: Del Rey, 2005, p. 460.

DANTAS, Bruno. Lei de Recursos Repetitivos pode se tornar obsoleta. Consultor Jurídico, 2 de maio de 2010 . Entrevista concedida a Eurico Batista. Disponível em: <http://www.conjur.com.br/2010-mai-02/entrevista-brunodantas-integrantes-comissao-cpc>. Acesso em 24 abr. 2015.

DIDIER JR., Fredie. Curso de Direito Processual Civil. I $7^{\mathrm{a}}$ ed., Salvador: JusPodivm, 2015.

GAIO JÚNIOR, Antônio Pereira. Incidente de resolução de demandas repetitivas no projeto do novo CPC. In: Revista de Processo, ano 36, n. 199. São Paulo: Editora Revista dos Tribunais, setembro/20 I I.

Recebido em: 27/04/2015

Aprovado em: 02/08/20 I 5 


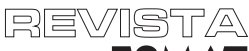

ESMAT

ESMAR CUSTÓDIO VÊNCIO FILHO 